\title{
LIGHTWEIGHT IT-GOVERNANCE FOR NGOS: AN UNRESOLVED CHALLENGE
}

\author{
Marie-E. Godefroid ${ }^{1}$, Vincent Borghoff ${ }^{2}$ and Ralf Plattfaut ${ }^{2}$ \\ ${ }^{1}$ Universität Siegen, Germany \\ ${ }^{2}$ Fachhochschule Südwestfalen, Germany
}

\begin{abstract}
IT consumerization and the introduction of lightweight IT, e.g., whiteboards and robotic process automation (RPA), have led to new IT governance challenges. This phenomenon is of particular importance in the context of non-governmental organizations (NGOs) where IT departments typically lack funds and employees are not yet as skilled as in the private sector (Merkel et al. 2007). The literature presents several governance models for lightweight IT that researchers have not yet compared to NGOs' current IT governance practices and needs. However, a deeper understanding of IT governance is quite important as the risks of lightweight IT turning into Shadow IT could jeopardize the value lightweight IT can create across the NGO value chain. Therefore, this article presents the results of focus group discussions with IT leaders from several large international NGOs. Their perspectives on IT governance overlap with the most prominent lightweight IT governance models in literature by Bygstad and Iden (2017). Aspects of all four models (central control, bi-modal, platform, and laissez-faire) are apparently in use in NGOs. The interviews also revealed the need for different IT governance models on different organizational levels of international NGOs. This extends existing insights on lightweight IT governance. The results indicate avenues for further research.
\end{abstract}

\section{KEYWORDS}

NGO, Non-Governmental Organizations, IT Governance, IT Governance Models, Lightweight IT, IT Consumerization

\section{INTRODUCTION}

IT consumerization and the development of ever new "lightweight" technologies lead to the adoption of digital technologies in everyday life - both business and private - and changes IT governance requirements. IT consumerization describes the trend that the experiences employees make as consumers also change their expectations and practices regarding IT in the workplace. This effect can go as far as Bring Your Own Device (BYOD), where consumers use private resources for business purposes. IT consumerization and BYOD naturally also influence IT governance as the easy access to technologies democratizes and individualizes its use (Gregory et al. 2018).

This phenomenon is especially prominent for so-called "lightweight" technologies. Bygstad introduced this term in 2015 to describe technologies like mobile frontend tools, e.g., whiteboards and frontend automation, e.g., RPA. The assumption is that these lightweight technologies require a different knowledge regime than traditional heavyweight systems, e.g., ERP systems, to allow for experiments and innovative solutions. Users can easily implement these technologies by themselves without the help of the IT department. This type of technologies opens up interesting new avenues for innovation. Process owners can now easily solve their problems on their own. Nevertheless, at the same time, this can increase the risk for Shadow IT if lightweight IT is not properly governed. The ensuing security risks and organizational inefficiencies require mitigation (Klotz et al. 2018).

This trend is significant for non-governmental organizations (NGOs) as they have lacked the funds, and the employee skillset in the past for large-scale IT investments (Merkel et al. 2007). Therefore, the challenges of IT consumerization and lightweight IT for IT governance should be even more prominent in this sector. Suppose well-funded commercial IT departments already struggle to fit this trend into their IT governance models. In that case, IT governance must be even more challenging to NGO's IT departments that, at the same time, face high accountability requirements (Burkart et al. 2018). 
The literature presents the several solutions for IT governance models in lightweight settings. However, these governance models are neither fully established theoretically nor proven to function practically across sectors. So far, no publications are eliciting the exact requirements for lightweight IT governance in the social sector or testing the transferability of general solutions for the social sector. However, this is an essential question as several cases show the value the use of lightweight technologies can have across the value chain (Le Dantec and Edwards 2008, Voida et al. 2011, Zhou and Pan 2016, Dey 2018, Jena et al. 2018). This paper aims to answer three research questions to close this gap:

- RQ1: What are the challenges in lightweight IT governance for social sector organizations?

- RQ2: What governance models do NGOs use for lightweight IT building on Bygstad and Iden?

- RQ3: Do these models exhaustively describe the governance requirements found in the social sector?

The remainder of the paper structures as follows: Chapter 2 presents the theoretical background regarding lightweight IT and corresponding IT governance. Chapter 3 describes the method in more detail that has led us to the findings that chapter 4 presents. Their implications and limitations, as well as further research questions, appear in the final chapter 5.

\section{BACKGROUND}

\subsection{IT Consumerization and Lightweight IT}

With the consumerization of IT, a new type of information systems takes hold in organizations' IT (Niehaves et al. 2012). Software solutions, initially developed for consumer use, are more and more applied within professional contexts (Harris et al. 2012). While traditional IT systems usually operate as back-end solutions, relying on databases and transactional resources (Lublinsky et al. 2013), these consumer software solutions are primarily user-centric frontend systems (Bygstad 2017).

As these systems are much more focused on the user, consumer systems show less complexity (Øvrelid et al. 2018). Therefore, these systems can be seen as comparable to the stream of lightweight IT introduced by Bygstad, which describes a more process-centric software approach. Lightweight systems within organizational contexts are generally business owned and therefore lie outside the IT department's realm. This governance approach facilitates process and business innovation, as a more exploratory approach can be incorporated (Bygstad 2017). The technological stream of lightweight IT is set in contrast to heavyweight IT, representing the more traditional IT systems, such as enterprise resource planning systems. Heavyweight IT is defined as complex back-end systems, owned by the IT department and developed with a quality and security focus, rather than innovation (Bygstad 2015).

Decentral development and deployment of IT may risk bypassing established governance structures (Kopper et al. 2018). Therefore, decentralization may lead to a rise of Shadow IT within an organization and foster the risk of security and regulatory breaks (Koch et al. 2014). IT governance often lacks models and appropriate organizational set-up to regulate and oversee the decentral and rapidly developing utilization of lightweight and consumer systems (Gregory et al. 2018).

\subsection{Lightweight IT Governance Models}

In the research community, the governance of lightweight IT has caused considerable debate. In his initial publication on the subject, Bygstad (2015) proposed a loose coupling in terms of technology, organization, and standards. For the specific case of RPA (Lacity and Willcocks 2015) reacted with research calling for a tighter coupling. Bygstad and Iden then, in 2017, proposed four governance models for lightweight IT in general. In 2019 (Osmundsen et al. 2019) further explored mitigation mechanisms for lack of control mechanisms and lack of end-to-end process view that a loose coupling entails. As these observations focus primarily on RPA, we will base our research on the more general governance models:

Bygstad and Iden (2017) propose a framework consisting of four distinct models for lightweight governance. They build their model based on the two dimensions of securing and resourcing (Ghazawneh and Henfridsson 2013). Resourcing depicts the intention to exploit the advantages of a lightweight solution in terms of inherent innovativeness and loosely regulating the development and implementation. As the second 
dimension, securing describes the process of restricting or limiting lightweight IT, e.g., by establishing regulations and policies or limiting resources.

In their framework Bygstad and Iden adapt known governance models to the specifics of lightweight IT (Bygstad and Iden 2017): The central control model leaves IT solutions' responsibility within the IT department, involving decisions concerning the development and implementation of solutions. This model allows direct and tight control as well as transparency concerning systems used within an organization. The bimodal approach splits the responsibility between the IT and business sides. The development process shifts to the operational business side; the decision about implementation stays within the realm of IT. A separate lightweight department oversees the development process. This separation allows for better resourcing without neglecting security. The laissez-faire model prohibits the IT department's involvement in the development and implementation of lightweight solutions, relying on decentralized operated standalone systems. While it facilitates innovation, this model's disadvantages are the foremost lacking scalability and appearing security issues. The platform model sees heavyweight solutions as a core system, to which the lightweight solutions link, according to set up regulations and technical specifications strictly. This model offers a compromise between securing and resourcing but requires a robust infrastructure and is, therefore, most appropriate for larger organizations. This governance model strongly depends on the use of boundary resources, which depict a collection of technical and functional requirements and specifications for applications in interaction with central IT (Ghazawneh and Henfridsson 2010).

\section{METHOD}

To answer our research questions, we follow a qualitative approach, based on focus groups as our primary data source. We invited five representatives from different international NGOs to discuss the use of information systems within their organizations with a specific focus on established governance approaches. This focus on the perspective of the IT department is intended as a first approach regarding the topic. Further research into the business perspective will be necessary to ensure a comprehensive view. All participants were invited based on their knowledge and involvement regarding the use of IT and information technology in general and profound knowledge about the organizational and business side. Also, the participants were selected based on organization size, revenue, number of employees, and a focus within the non-governmental domain to represent a broad spectrum of organizations (Table 1). For data gathering, we conducted two focus groups with participant three participating in both groups. The discussions were recorded and transcribed for later analysis.

Table 1. Composition of the focus groups

\begin{tabular}{llll}
\hline Focus group & Participant & Organization focus & Number of employees \\
\hline 1 & P1 & Christian relief and development agency & $>1,000$ \\
1 & P2 & Long-term development and disaster relief organization & $>3,000$ \\
1 and 2 & P3 & Humanitarian and developmental assistance to children & $>40,000$ \\
2 & P4 & Catholic humanitarian agency & $>5,000$ \\
2 & P5 & Humanitarian aid and refugee assistance & $<100$ \\
\hline
\end{tabular}

We use Bygstad's and Iden's (2017) governance models for lightweight IT as our research lens for the analysis. Therefore, all transcripts were coded by two of the authors according to the use of each specific governance model. We moreover code by factors that condition a particular type of governance and the challenges that arise concerning the governance of lightweight solutions and applying the individual governance models. We then discussed the coding results to ensure the validity of the results and minimize potential researcher bias (Chenail 2011). 


\section{FINDINGS}

NGOs have specific requirements regarding IT governance: The demand for high data security appears to be most central and has all information regarding financial processes on platform systems. Nonetheless, different parts of the organization employ very various technologies and framework conditions in developing countries. Overall, there are substantial local differences in IT equipment and framework conditions on the organizations' different levels, therefore more divergent requirements than in comparably large companies in the private sector.

\subsection{Challenges for Lightweight IT Governance}

Our interview partners mentioned the main challenge regarding lightweight IT governance was the balance between giving people the freedom to innovate to solve their problems and standardization. One of them described these contrasting goals as follows: "But there are kind of two elements there one is the governance: [...] To make sure that you do not have a jungle of applications [...] Because almost by rights you are trying to democratize things. Furthermore, you are trying to give people the chance to build these things and solve their problems, build their solutions, but at the same time you have to develop like a cohesive or kind of coherent infrastructure for people to use." (Focus group 2)

As our interview partners lead the IT departments of organizations that span several countries and bring together individuals with very different needs, they stressed their struggle for standardization. This struggle appears to be especially challenging as users can often implement lightweight IT solutions without the IT department's help. For example, one of our interview partners stated: "I think that creates its little challenges when you have the lightweight IT because you know if you're tasked with supporting a global system. You kind of want to have standards and standard solutions. And you have this tension we're you are going to say here I give you the solution like broadly we are a Microsoft shop: Here's our standard box of solutions. But I don't like your standard box of solutions. I want to use this other solution that is outside of this. You know, because this suits my particular need, and your one is a bit cumbersome for me. I could ask you, and you could tell me not to use it, or because it is on the web, I can just sign up, and I can go off, and I can just do it without asking permission." (Focus group 2) Researchers typically identify this IT use by business without the IT department's approval or even knowledge as Shadow IT. The literature cites different causes for developing this phenomenon ranging from perceived shortcomings of the IT department to particular business needs (Klotz et al., 2018). In our interviews, the IT leaders perceived the focus on local needs as the main driver: "They see their own particular problem, in their own particular time frame, and they're not concerned about whether or not they'll be able to share that data with lots of other partners nine months later. You know, not their problem, they just want to fix their particular problem." (Focus group 2)

On the other hand, they also emphasized the potential for innovation on the local level, which they accompany diligently. Even though or maybe because of limited means, these parts of the organization come up with very innovative solutions: "The folks out in the field have worked with minimal, everything. And so, they're all MacGyver out there. They all find ways of getting things done. And sometimes those ways are very innovative, and we can use those and sometimes they cause problems." (focus group 2) Such supervision is necessary as they found that nonregulated innovation can create non-scalable and unsafe systems: "If you leave it to everyone's whim, you get Bill and Ted's Excellent, whatever system. And then that's what's brought into the environment, and it's not secure, it doesn't scale. And it doesn't do what we want it to do" (Focus group 2).

These two sides of the governance challenge led them to postulate that "you got to be able to do both and manage both. But you also have to be the gentle dictator in some cases" (Focus group 2). This duality leads us to discuss different governance models in the next chapter as the "gentle dictator" was not the model all our interview partners follow. 


\subsection{Governance Models}

\subsubsection{Central Control Model}

Several NGOs apply a central control model due to a focus on data security. From our discussion, we understood that data security seems to have the highest priority within governance for NGOs. Therefore, several participants utilize a centrally controlled governance model. This model implies that there are strict guardrails to ensure a standardized approach: " But we have to set guardrails, and those guardrails are, okay, you want a program or an application to do X, great, we will work with you, we will figure out if there's something within the ecosystems we already have. And if there isn't, then let's figure out how we get that in how its proper, properly used, and, and how it fits the security posture" (Focus group 2). The possibility of data contamination or malicious intrusion into the database when implementing new systems leads to more centrally governed structures. Primarily due to dependency on funding through donors. These are often concerned with their data safety as well as that of the beneficiaries. For example, one participant firmly stated: "Beneficiaries are our number one priority. [...]And if we don't protect them, and we don't protect their information, okay and we allow a free for all, [...] We lose funding from donors, for our beneficiaries, because we don't have accurate information because we can't protect that information" (Focus group 2).

Nevertheless, when using a central control model, participants also try to support local innovation to a certain extent:" There's a lot of very creative people out in the field when you have nothing when you have zero, you get really creative. It is the hierarchy of survival, and then that applies to the hierarchy in IT", (Focus group 2). This hierarchy is essential as local needs are best understood on the local level and not by the international headquarters' IT departments. This division of labor requires, however, a specific response mechanism: "So, you know, you have to have this sense and respond to the kind of, I think, every sentence and respond kind of the mechanism with the folks out in the field to understand what problems are they trying to deal with? And how are they doing it? And could we take that and scale it in some form or fashion? And, and if we can, then we need to give them tools to help them do the work that they're doing." (Focus group 2).

\subsubsection{Laissez-Faire Model}

Several of our participants described a model where the IT department is only in a supporting role, and no central control exists. This model can go so far that business implements IT systems without significant interaction with the IT department. Participants described this model to be exceptionally responsive to local needs and to increase innovation. Nevertheless, they were also keenly aware of potential drawbacks. For example, this model requires a tolerant failure culture within the organization: "And we need to, like, commit to allowing people to try these types of things, and an understanding that it might not work all of the time, you know, and that we need to try and even if, even if we fail, that's okay" (Focus group 1). This description is in line with Bygstad's description of how to apply laissez-faire governance, as security or scalability issues are not neglected but seen as less important than the innovation focus (Bygstad 2015).

\subsubsection{Bi-Modal Model}

We also find evidence for the use of a bimodal IT approach. Focus group participants stated that they distinguish responsibility according to the extent of effort to be made. For example, one participant described: "When we have both [...] the programme people are the ones who are doing the small maintenance of it, but maybe the IT can think broader an even bring more improvement [...]" (Focus group 1). This description implies that governance, in this case, is handled differently for lightweight and heavyweight solutions. Whereas the heavyweight, core system solutions stay within the IT department, lightweight solutions are governed and maintained by the business side. This division of labor is in line with a more general definition of bi-modal IT governance, which assumes that architectures, processes, and organization are different for both modes (Horlach et al. 2016, Haffke et al. 2017, Jöhnk et al. 2019). Bygstad and Iden, however, outlined a specification to the model in which responsible experts develop lightweight solutions in separate processes, but implementation still lies within the "heavyweights" IT department's responsibility (Bygstad and Iden 2017). 


\subsubsection{Platform Model}

The main reason for choosing a platform solution for governance seems to be retaining control over the core and standard processes relevant to the organization. For example, one participant outlined:" I don't want people innovating on how to pay an invoice [...]. So, these are just standard processes. And those, there is a dictatorship on that kind of stuff" (Focus group 1).

Platform approaches enable IT departments to set clear guidelines for these processes and set regulations to implement lightweight solutions, touching on those processes. Within the discussion, it became clear that lightweight IT's inherent innovation is welcome, enabling operational staff to build fitting solutions for specific individual issues on time. This finding is in line with the concept of boundary resources, defining the elementary necessities for applications interacting with the core system and using its infrastructure (Ghazawneh and Henfridsson 2013). Nevertheless, some participants also mentioned the necessity of a governance model for different organizational levels, respectively of different granularity: "I think there are different layers and, of course, not so easy to control because there is a layer of global reporting and steering. And they're you need the discipline. But then there is, of course, a layer of a lot of local needs also local reporting needs to authorities and so, and this is something where you have to give people freedom because you will not be able to manage. And then there is a layer of very local, very local, local, local needs. Let's say in a unit, in a village or in a facility" (Focus group 1). This statement collides with the concept of clear and holistic resources, defined for all applications and domains within a platform. Therefore, when applied to lightweight IT, the concept of a platform-based governance model seems not to cover all necessities of international NGOs.

\subsection{Levels of Governance}

The IT leaders described that often due to historically grown structures, they had different solutions in use at the same time by different organization levels. Often this was due to different level of technology use, e.g., having a fully-fledged financial system vs. using spreadsheets to capture relevant data: "We have our financial system only in our HQ, but our country offices would have their spreadsheets as late as last year and doing their analysis and sending that by the end of the month to our HQ." (Focus group 1) These differences can also be on the local level, e.g., different countries using different solutions, but mostly there seem to be differences between systems used by the headquarter and the country-specific or local organizations.

Apparently, due to the challenge in balancing local innovation and central standardization needs, IT leaders feel that some degrees of freedom on the local level are necessary. Much attention in this context focuses on data. As one of the main interaction points between the different levels of the organization, data on beneficiaries is especially critical as donors require increasing data quality. IT leaders described this as a pull for specific technological solutions in the field. A layered approach that still allows the local level to use their preferred tools can, however, achieve such solutions: "Use this [local] data gathering tool but send the data in via a proper interface that we give you. So, it fits the rest of [what] we produce here. "(Focus group 1).

IT leaders identified three levels or layers on which IT systems are operated and derived different governance needs for each level as detailed in section 4.2.4 Platform model. These findings imply that the four archetypes of lightweight IT governance models identified in the literature (Bygstad and Iden 2017) do not fulfill NGOs' requirements. Therefore, we have to consider organizations that use different models for different layers of their organizations or even different parts of their systems. Put simply, this means that we have multiple governance models in one organization at a time. Multiple models increase the complexity as the models' interaction requires conceptualization and extension of existing theories. However, solving this challenge is worth the effort as a functioning IT governance can prevent lightweight IT from turning Shadow IT and unlock the innovation potential on all levels of the organization. 


\section{DISCUSSION}

We conducted focus groups with IT leaders from international NGOs to answer our research questions. This led us to three major findings. Firstly, the main challenge in lightweight IT governance for social sector organizations is the balance between local needs and central standardization. Here freedom for innovation on the local level has to be prioritized against a scalable and secure IT infrastructure on the global level. Secondly, we were able to find evidence for all four governance models for lightweight IT that Bygstad and Iden identified for the healthcare sector. These models appear to coexist as participants described different models in the context of different parts of their organization. Thirdly, we also found that these models do not exhaustively describe the social sector's governance requirements. This finding adds the dimension that organizations can use multiple models at different levels of the organization.

These findings have theoretical as well as practical contributions. Our findings confirm the four governance models identified for lightweight IT so far and compliment them with additional sectorial requirements. This could be a starting point for further research on types of lightweight IT governance models and possible specific requirements of other sectors. We were also able to shed light on one of the main challenges IT leaders in NGOs need to solve to unlock lightweight IT's full potential. Practitioners can use our results to reflect on their governance approaches and possibly use the adapted, transferred models from literature to make their approaches even more systematic. Such a theoretical approach could also help reflect the goal (innovation or standardization) they want to focus on at the moment.

Our research naturally comes with some limitations. The four models identified by Bygstad and Iden (2017) stem from the platform IT's specific research stream. Therefore, the results might not apply to general IT Governance. They might also hold only for certain NGOs as very small, national NGOs, for example, might have different characteristics and subsequent needs. Also, the results to not yet reflect a comprehensive view as the business perspective is still missing. Finally, as the subset of large international NGOs' IT leaders is relatively small, our focus groups were also quite small, with 5 IT leaders in total. Nonetheless, this qualitative approach allowed us to explore our topic in detail and create a meaningful starting point for further research.

Our research shows that this is just the starting point and that further research is essential to explore the phenomenon. We believe that this should center around three topics: Types of models, levels of governance, and governance strategies: Firstly, we believe that more research into possible governance models is necessary. We were able to show the transferability for the social sector, but there might be further specific requirements for other sectors. Exploring this in detail would allow researchers to better understand forming mechanisms for IT governance models and practitioners to learn from others. Possible questions could be: How are suitable governance models for lightweight IT designed, e.g., are there further additions to Bygstad and Iden (2017)? Are they applicable to every sector? What factors determine the use of a particular model? What are the consequences (advantages and disadvantages) of using a particular model? Secondly, to place the lightweight IT governance models more firmly in the overall IT governance research stream, it would be essential to map them to the established IT governance mechanism frameworks, e.g., those by (Weill and Ross 2004) or (van Grembergen et al. 2004). Possible questions could be: How do the governance models from lightweight IT research translate into established IT governance mechanisms? Are there possibly more models that should be evaluated based on a simple computation of the mechanisms? Are the identified dimensions for "traditional" IT governance sufficient for lightweight IT, or is it necessary to add elements or even dimensions? Finally, we found that apparently, different governance levels are necessary - at least for large international NGOs. Conceptualizing this further would allow for a more detailed analysis and, in the end, for better governance that captures the needs of the organization's different levels. Possible questions would be: Can there be different models for different levels or technologies? (Due to degree of integration with the central system, criticality of systems, processes involved). For the NGO example, one could evaluate this along the NGO value chain (Programme Design, Fundraising, Fund Management, and Programme Delivery) in expert interviews (Snow et al. 2016). Such an approach would allow testing for different governance requirements along with the different activities of an NGO. Are there any governance non-critical lightweight IT use cases? Is there a "non-governance" level? To what extent can models exist in parallel, and what are the consequences? 


\section{REFERENCES}

Burkart, C. et al, 2018. Funds allocation in NPOs: the role of administrative cost ratios. Central European Journal of Operations Research, 26 (2), 307-330.

Bygstad, B., 2015. The Coming of Lightweight IT. In: European Conference on Information Systems (ECIS) Proceedings. Münster, Germany.

Bygstad, B., 2017. Generative 9nnovation: A comparison of lightweight and heavyweight IT. Journal of Information Technology, 32 (2), 180-193.

Bygstad, B. and Iden, J., 2017. A governance model for managing lightweight IT. In: Á. Rocha, et al., eds. Recent advances in information systems and technologies. Cham: Springer International Publishing, 384-393.

Chenail, R.J., 2011. Interviewing the investigator: Strategies for addressing instrumentation and researcher bias concerns in qualitative research. Qualitative Report [online], 16 (1), 255-262. Available from: https://eric.ed.gov/?id=EJ914046 [Accessed 3 Jan 2021].

Dey, N., 2018. Social network analytics: Computational research methods and techniques. Amsterdam, NL: Elsevier.

Ghazawneh, A. and Henfridsson, O., 2010. Governing third-party development through platform boundary resources. In: International Conference on Information Systems (ICIS) Proceedings, 1-18.

Ghazawneh, A. and Henfridsson, O., 2013. Balancing platform control and external contribution in third-party development: the boundary resources model. Information Systems Journal, 23 (2), 173-192.

Gregory, R., et al., 2018. IT Consumerization and the transformation of IT governance. MIS quarterly, 42 (4).

Haffke, I. et al, 2017. The Transformative Role of Bimodal IT in an Era of Digital Business. In: Hawaii International Conference on System Sciences (HICSS) Proceedings.

Harris, J. et al, 2012. IT Consumerization: When gadgets turn Into enterprise IT tools. MIS Quarterly Executive, 11 (3), 99-112.

Horlach, B. et al, 2016. Bimodal IT: Business-IT alignment in the age of digital transformation. In: Multikonferenz Wirtschaftsinformatik (MKWI) Proceedings, 1417-1428.

Jena, S. et al, 2018. Development of women through digitalization in odisha. CPUH-Research Journal, 3 (2), $262-265$.

Jöhnk, J. et al, 2019. Juggling the paradoxes - Governance mechanisms in bimodal IT organizations. In: European Conference on Information Systems (ECIS) Proceedings.

Klotz, S. et al., 2018. Causing Factors, Outcomes, and Governance of Shadow IT and Business-Managed IT: a Systematic Literature Review. International Journal of Information Systems and Project Management, 7 (1), $15-43$.

Koch, H. et al., 2014. Consumerization and IT department conflict. In: International Conference on Information Systems (ICIS) Proceedings.

Kopper, A. et al., 2018. Shadow IT and business-managed IT. International Journal of IT/Business Alignment and Governance, 9 (2), 53-71.

Lacity, M.C. and Willcocks, L.P., 2015. The IT Function and Robotic Process Automation. The Outsourcing Unit Working Rearch Paper Series Paper 15/05: London School of Economics.

Le Dantec, C.A. and Edwards, W.K., 2008. The View From the Trenches: Organization, Power, and Technology at Two Nonprofit Homeless Outreach Centers. CSCW.

Lublinsky, B. et al, 2013. Applied SOA: Service-oriented architecture and design strategies. Hoboken, N.J.: Wiley.

Merkel, C. et al., 2007. Managing technology use and learning in nonprofit community organizations: methodological challenges and opportunities. In: Symposium on computer human interaction for the management of information technology (CHIMIT '07) Proceedings. New York, USA: Association for Computing Machinery.

Niehaves, B. et al, 2012. IT Consumerization - A Theory and Practice Review. In: Americas Conference on Information Systems (AMCIS) Proceedings. Red Hook, NY: Curran, 9-12.

Osmundsen, K. et al, 2019. Organizing robotic process automation: Balancing loose and tight coupling. In: Hawaii International Conference on System (HICSS) Proceedings. Grand Wailea, Maui, Hawaii, USA.

Øvrelid, E. et al, 2018. Creating Coordinative Paths from admission to discharge: The role of lightweight IT in hospital digital process innovation. In: Hawaii International Conference on System Sciences (HICSS) Proceedings.

Snow, G. et al, 2016. NGO Reference Model: An enabler for digital transformation [online]. Available from: https://www.ngoreferencemodel.org/.

van Grembergen, W. et al, 2004. Structures, processes and relational mechanisms for IT Governance. In: W. van Grembergen, ed. Strategies for Information Technology Governance: IGI Global, 1-36.

Voida, A. et al, 2011. Homebrew databases: complexities of everyday information management in nonprofit organizations. In: SIGCHI Conference on Human Factors in Computing Systems (CHI '11) Proceedings. New York, USA: Association for Computing Machinery.

Weill, P. and Ross, J.W., 2004. IT Governance on one page. SSRN Electronic Journal.

Zhou, H. and Pan, Q., 2016. Information, community, and action on sina-weibo: How chinese philanthropic NGOs use social media. Voluntas, 27, 2433-2457. 